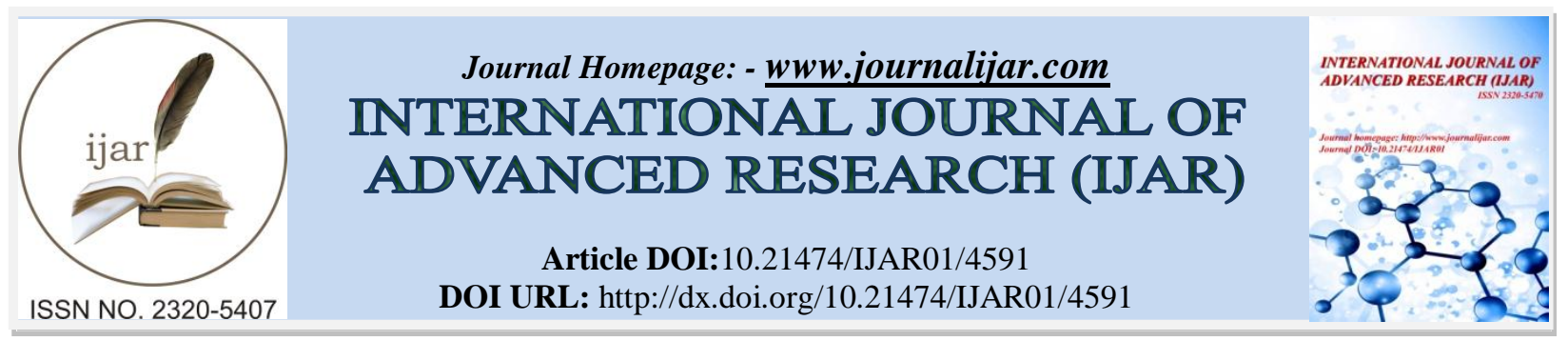

RESEARCH ARTICLE

\title{
PARAMETRIC STUDY ON THE ENERGY EFFICIENCY, REDUCE OPERATION COST AND ENVIRONMENT IMPACT OF STABILIZATION UNITY IN OIL PROCESS.
}

Ahmed Ould Brahim and Souad Abderafi.

Laboratory for Analysis and Synthesis of Industrial Processes (LASPI), Mohammadia School of Engineers (EMI) Mohammed V University in Rabat, Ibn Sina, B.P. 765, Agdal, , Rabat,10090, Moroc.

\section{Manuscript Info} (1.......................

\section{Manuscript History}

Received: 24 April 2017

Final Accepted: 26 May 2017

Published: June 2017

\section{Key words:-}

Energy efficiency, Energy consumption, $\mathrm{CO}_{2}$ emission, Impact Environment, Climate change, stabilization column.

\section{Abstract}

In the light of the emissions associated with fossil fuel combustion used in industry and their associated health and environmental impacts, the study of energy efficiency and reduce the greenhouse gases emissions of industry becoming increasingly attractive from various researches. The separation of petroleum fractions are energy and power intensive processes and contribute significantly to the greenhouse gases emissions (e.g. carbon dioxide) though contribute to climate change. The main objective of this study is to get a better use of energy, reduce impact environmental and operation cost for the distillation column of petroleum fractions, especially the gasoline stabilization column. To do this, the steps followed for the calculation of distillation columns were presented. Simulations result using Soave-Redlich-Kong (SRK) thermodynamic model, with the help of CHEMSEP and Pro II softwares were validated on the basis of experimental data collected from crude oil refinery. Hence, a technical feasibility study was carried out, using numerical simulation, to run the stabilization column at optimum values of pressure, reflux ratio and feed tray to optimize the energy consumption, energy efficiency, carbon dioxide emissions from the furnace (Reboiler) and operation cost of the column were calculated, before and after optimization. The results allowed us to highlight the effect of these parameters on the energy consumption of the stabilization column. From an economic point of view, stabilization column with optimal parameters may contribute to a decrease in expenses related to the energy consumption and carbon dioxide.

Copy Right, IJAR, 2017,. All rights reserved.

\section{Introduction:-}

The distillation operation is one of the most polluting industries that have impacts on the environment, because the greenhouse gases increase within creasing energy consumption, which also produces an increase in the operating cost of energy. This environment impact can cause serious damage to the human health. The international commitment to keep the increase in long-term average temperatures to below two degrees Celsius $\left(2^{\circ} \mathrm{C}\right)$, relative to pre-industrial levels, will require substantial and sustained reductions in global emissions. The 196 Parties to the United Nations Framework Convention on Climate Change (UNFCCC) agreed on a long-term global objective, as part of the package of decisions at COP16 in Cancun in December 2010 to COP22 Marrakesh November 2016 [1]. 
Greenhouse-gas emissions from the energy sector represent roughly two-thirds of all anthropogenic greenhouse-gas emissions and $\mathrm{CO}_{2}$ emissions from the sector have risen over thepast century to ever higher levels. Reducing $\mathrm{CO}_{2}$ emissions is an absolute necessity and expensive challenge to the chemical process industries in order to meet the environmental targets as agreed in the Kyoto Protocol [3]. Among these energy sectors, distillation process is considered as the primary separation process used in industrial chemical processing. While, it has many advantages, the significant energy requirement is one major drawback which can significantly influence overall plant profitability. It is quite energy intensive and accounts for a large part of industrial energy consumption [4, 5]. Increasing energy costs deter energy consumption as do tighter environmental regulations regarding fossil fuel use, leading to research into new and more efficient separation methods [4, 6]. Effective action in the energy sector is therefore essential in the fight against the climate change problem. So improving the energy efficiency of industry and protecting of the environment becomes a priority for technician- scientific, managers, engineers and scientific researchers. The literature review shows that a large number of research studies have been carried out to optimize most separation units of petroleum fractions [7, 8]. Various researches were made to have on optimization of the energy efficiency of refinery units. The most common optimization methods are the optimization of operating conditions of process and/or energy integration analysis [9].

The objective of this study is to improve the energy efficiency, reducing $\mathrm{CO} 2$ emission and operation cost of distillation column in an existing industrial oil refinery, by studying the parametric sensitivity to determine the optimum values of the operating conditions

\section{Description of process:-}

The petroleum is a complex mixture of different hydrocarbons fractions, small amounts of sulfur and trace amounts of oxygen, nitrogen and metals. Separation is effected by heated the mixture to an elevated temperature of about $400^{\circ} \mathrm{C}$, then injected into an atmospheric pressure distillation column. Distillation is the separation of completely miscible mixtures of liquids according to the difference of the boiling point and volatility of the components in the mixture. However, the lighter products, as butane, are obtained at the head of the column and the heavier components such as gasoline, kerosene and gas oil (diesel oil) remains successively lower [10]. As for the residue that cannot be distilled, even at very high temperatures remain at the bottom of the distillation column. Of the tray 13 of distillation column is drawn off the naphtha which feeds stabilization column. The purpose of the latter is to achieve the separation of the total naphtha in its various constituents and prepare the load of catalytic reforming [11]. Stabilization column is equipped with a partial condenser, 30 bubble cap trays and a reboiler (Figure 1).

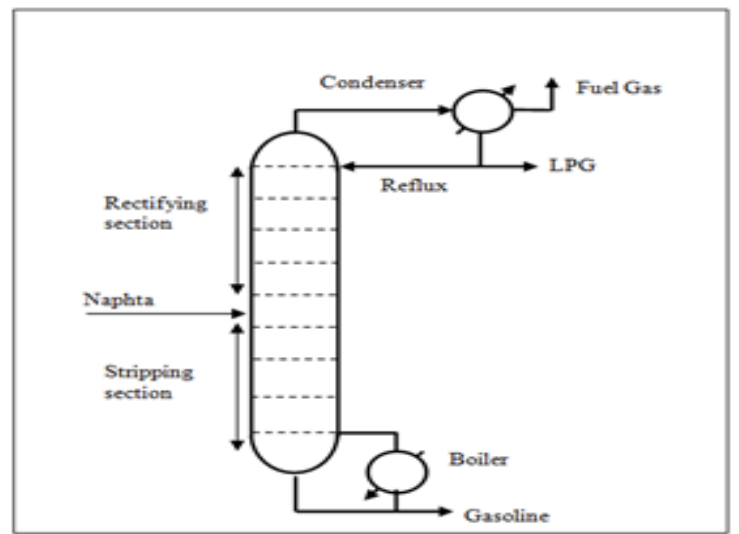

Figure1:- Diagram relating to the stabilization column

Stabilization column operation is similar to that of the atmospheric distillation column, except that it does not have the side streams. The power supply is disposed at the sixteenth tray (the trays are numbered from top of the column to bottom of the column). The effluent recovered at the column head is the fuel gas. At the first tray level of this column, we obtain the LPG consisting, principally of propane and butane. At the bottom of this column, we get a cut of heavy gasoline containing hydrocarbon chains type C6, C7, C8, C9 and C10 [12]. Carbon dioxide is generated mainly from furnaces, gas turbines and boilers. These utility devices are the energy consumers in the refining plants and are used to provide heat, steam and power to the process by burning a fuel. Therefore these units are key drivers 
in energy savings oriented projects and reducing environmental emissions impacts. Fuel is combusted when mixed with air, producing $\mathrm{CO}_{2}$ (Figure 2) [13].

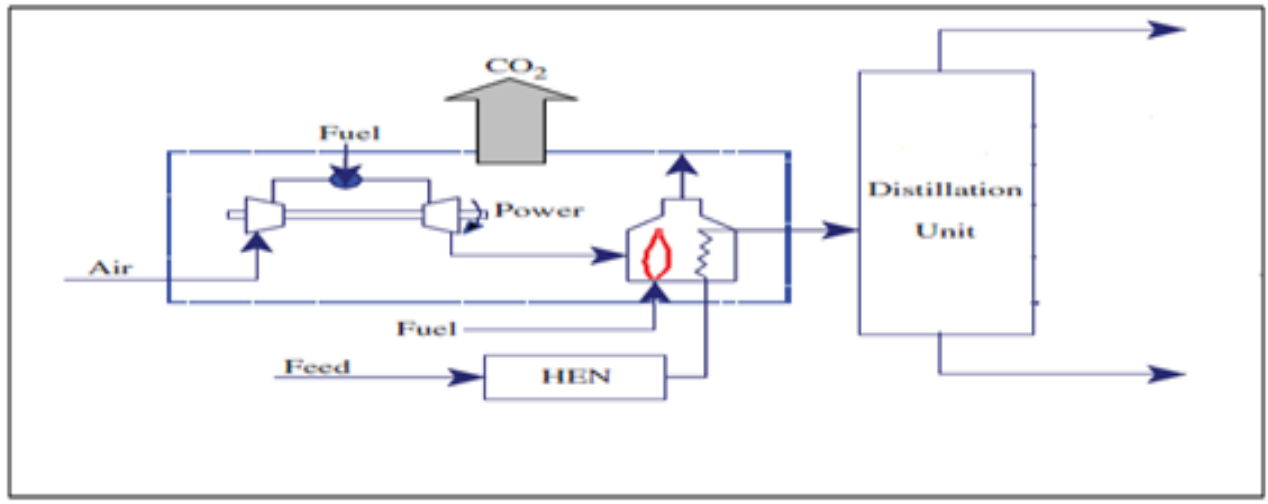

Figure 2:-Principle of $\mathrm{CO}_{2}$ emission on reboiler [13]

\section{Equations of Modeling:-}

The set of equations that govern the operation of the column is obtained using the equations of balance material, energy and the equations relating to conditions of Vapor-Liquid Equilibrium (VLE). Figure 3 shows the diagram for principle of an equilibrium stage. Each stage, $\mathrm{j}$ receives a diet feed $\mathrm{F}_{\mathrm{j}}$, a fluid flow, $\mathrm{L}_{\mathrm{j}-1}$ from the upper stage and a steam flow, $\mathrm{V}_{\mathrm{j}+1}$ of the lower stage, a liquid extraction $\mathrm{U}_{\mathrm{j}}$, a steam extraction $\mathrm{W}_{\mathrm{j}}$ and a heat input $\mathrm{Q}_{\mathrm{j}}$ can be considered [14]. All these equations required for modeling are written, at each tray of the column and are given below:

- Material balance equation is given by:

$$
L_{j-1} x_{i j-1}-\left(V_{j}+W_{j}\right) y_{i j}-\left(L_{j}+U_{j}\right) x_{i j}+V_{j+1} y_{i j+1} F_{j} z_{i j}=0
$$

* Energy balance equation is given by:

$$
L_{j-1} h_{j-1}-\left(V_{j}+W_{j}\right) H_{i j}-\left(L_{j}+U_{j}\right) h_{j}+V_{j+1} h_{j+1} F_{j} h_{F j}-Q_{j}=0 \text { (2) }
$$

Where, $\mathrm{V}$ and $\mathrm{L}$ are vapor and liquid flow rate, respectively (in $\mathrm{kg} / \mathrm{h}$ ); $\mathrm{U}$ and $\mathrm{W}$ liquid and vapor side stream flow, respectively (in $\mathrm{kg} / \mathrm{h}$ ).

* The heat quantities in the boiler and in the condenser are calculated from the following equations:

$$
Q_{1}=V_{2} h_{2}-\left(U_{1}+L_{1}\right) h_{1}-V_{1} h_{1}
$$

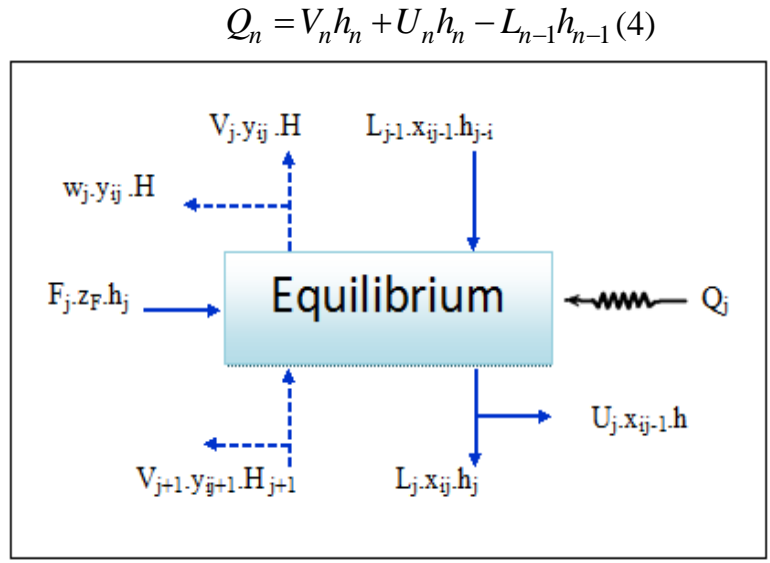

Figure 3:- Principle of an equilibrium stage

Where, $\mathrm{Q}_{1}$ is heat flow of condenser and $\mathrm{Q}_{\mathrm{n}}$ is heat flow of reboiler.

\section{Calculation of VLE:-}

The calculations of VLE are realized by mean of equality of temperature, pressure and fugacity in each liquid and vapor phase. The equation of the latter is written as: 


$$
f_{i}^{L}=f_{i}^{V} \text { (5) Where } f_{i}^{V} \text { and } f_{i}^{L} \text { are fugacities of component, i in vapor and liquid phase, respectively, at }
$$

the same temperature and pressure, expressed by:

$$
\begin{aligned}
& f_{i}^{L}=x_{i} \varphi_{i}^{L} P(6) \\
& f_{i}^{V}=y_{i} \varphi_{i}^{V} P(7)
\end{aligned}
$$

Where, $x_{i}$ and $y_{i}$ are the liquid and vapor phase mole fraction of component and $\varphi_{i}$, is fugacity coefficient of component, i.

\section{Thermodynamic model:-}

VLE calculation requires a thermodynamic model like an equation of state (EOS). Among the many cubic EOS of Van der Waals type currently available, the equation proposed by Soave-Redlish- Wong (SRK) is widely used due to its simplicity and flexibility, for hydrocarbons fractions [15]. This model has the following form for a pure component [16]:

$$
P=\left(\frac{R T}{V-b}-\frac{a(T)}{V(V-b)}\right)
$$

Where, $\mathrm{P}$ is the absolute pressure, $\mathrm{T}$ is the absolute temperature, $\mathrm{V}$ is the volume and $\mathrm{R}$ is the ideal gas constant. The volume and energy parameters of the SRK EOS ( $a$ and $b$ ), are calculated from the following equations:

$$
\begin{aligned}
& b=0.086640 \frac{R T_{c}}{P_{c}} \\
& a(T)=0.42748 \frac{\left(R T_{c}\right)^{2}}{P_{c}}\left(1+m\left(1-\sqrt{T_{r}}\right)\right)^{2}
\end{aligned}
$$

Where, subscripts $\mathrm{c}$ and $\mathrm{r}$ denote critical and reduced conditions, respectively; $\mathrm{m}$ depend on the acentric factor, $\omega$ :

$$
m=0.48+1.57 \omega+0.172 \omega^{2}
$$

For extending SRK EOS to mixtures, it is necessary to include composition. Many algebraic relations have been suggested for this purpose. We elected to choose those recommended for SRK EOS [16]. They are the classic Van der Waals one-fluid mixing rules, used to calculated $\mathrm{a}_{\mathrm{m}}$ and $\mathrm{b}_{\mathrm{m}}$ mixture parameters from:

$$
\begin{aligned}
& a_{m}=\sum_{i} \sum_{j} x_{i} x_{j}\left(a_{i} a_{j}\right)^{0.5}\left(1-k_{i j}\right) \\
& b_{m}=\sum_{i} x_{i} b i
\end{aligned}
$$

$\mathrm{k}_{\mathrm{ij}}$ is the binary interaction parameter between component, $\mathrm{i}$ and $\mathrm{j}$; with $\mathrm{k}_{\mathrm{ij}}=\mathrm{k}_{\mathrm{ji}}$ and $\mathrm{k}_{\mathrm{ii}}=0$

\section{$\mathrm{CO}_{2}$ Emissions Model:-}

In distillation column such as stabilization unit, $\mathrm{CO}_{2}$ is generated, mainly, from boilers or furnaces [12]. These devices are used to provide a heat and power to the process by burning a fuel. The fuel is combusted when mixed with air, producing only $\mathrm{CO}_{2}$, according to following stoichiometric equation:

$$
\mathrm{C}_{x} \mathrm{H}_{Y}+\left(x+\frac{y}{4}\right) \mathrm{O}_{2} \rightarrow x \mathrm{CO}_{2}+\frac{y}{2} \mathrm{H}_{2} \mathrm{O}
$$

Where, $\mathrm{x}$ and $\mathrm{y}$ are the carbon, $\mathrm{C}$, and hydrogen, $\mathrm{H}$, atoms number, respectively, present in the fuel compositions.

To estimate the $\mathrm{CO}_{2}$ emissions, the simple model given by Gadalla et al.[13] can be used. In this model, air is assumed to be in excess to ensure complete combustion of fuel. Hence, the flow of $\mathrm{CO}_{2}$ emissions (in $\mathrm{kg} / \mathrm{s}$ ), is related to the amount of fuel burnt, $\mathrm{Q}_{\text {Fuel }}$ in a heating device as follows:

$$
\left[\mathrm{CO}_{2}\right]_{\text {Emiss }}=\left(\frac{Q_{\text {Fuel }}}{N H V}\right)\left(\frac{C}{100}\right) \alpha
$$

Where, $\alpha=3.67$ is the ratio of molar masses of $\mathrm{CO}_{2}$ and atom of carbon, $\mathrm{C}$; NHV, is the net heating value of fuel equal to $39.771 \mathrm{~kJ} / \mathrm{kg}$, with a content of Carbon equal to $86.5 \%$ [12]. The amount of fuel burnt in a furnace can be related to the heat duty required by the process, $\mathrm{Q}_{\text {Proc }}(\mathrm{kW})$, and the efficiency of the furnace, $\eta_{\text {Furn }}$ as follows [13]:

$$
Q_{\text {Fuel }}=\frac{Q_{\text {Proc }}}{\eta_{\text {Furn }}}
$$


Through the use of a process simulator, CHEMSEP, for simulations, SRK equation of state that supports the widest range of operating conditions and the greatest variety of systems was used to predict the vapor-liquid equilibrium.

\section{Operation Cost Calculation:-}

After the energy efficiency optimization and reduction of $\mathrm{CO}_{2}$ emission, we seek to calculate the operation cost of industrial and optimized process to estimate the annual saving.

The operating cost of the process is calculated as the sum of operating costs for the condenser and reboiler of the column [19]:

$$
\begin{aligned}
& C_{O}=C_{r}+C_{C} \\
& C_{r}=C_{O . r} \cdot Q_{\text {reb }} \\
& C_{c}=C_{\text {O.c }} \times Q_{\text {cond }}
\end{aligned}
$$

Where: Co is operation cost, $\mathrm{Cr}$ reboiler cost and $\mathrm{Cc}$ the condenser cost

\section{Results and Discussion:-}

The experimental data are used to test the accuracy of thermodynamic simulation model. These datawere collected from a sample of the stabilization column (Table 1). The feed of this unit derived from the atmospheric distillation is composed of traces of $\mathrm{H}_{2}$ and $\mathrm{H}_{2} \mathrm{~S}$, small amounts of the hydrocarbon type $\mathrm{C}_{1}, \mathrm{C}_{2}, \mathrm{C}_{3}, \mathrm{C}_{4}$ and $\mathrm{C}_{5}$, as well as a heavy gasoline fraction containing hydrocarbon chains of type $\mathrm{C}_{6}, \mathrm{C}_{7}, \mathrm{C}_{8}, \mathrm{C}_{9}, \mathrm{C}_{10}$ and traces of $\mathrm{C}_{11}$. The Fuel Gas is recovered at the top of the column. At the first tray, the LPG is obtained, at a pressure equal to 13.7 bar. The stabilized gasoline is recovered at the bottom column, at a pressure equal to 14.1 bar. Using the SRK EOS with $\mathrm{k}_{\mathrm{ij}}=0$ and with the help of the Pro II, process simulation software, the calculated results are compared to the experimental data by calculating the error thanks to the following relationship:

$$
E(\%)=\frac{\left|V_{e}-V_{c}\right|}{V_{e}} \times 100
$$

Where, $\mathrm{V}_{\mathrm{c}}$ and $\mathrm{V}_{\mathrm{e}}$ are the calculated and the experimental values, respectively.

This comparison allowed us that the results are satisfactory, if we consider the experimental error [17].

Table.1:- Experimental data for stabilization column.

\begin{tabular}{|c|c|c|c|}
\hline Compound & Feed & Gasoline & LPG \\
\hline $\mathrm{N}(\mathrm{kmol} / \mathrm{h})$ & 84716.09 & 65371.6 & 10964.3 \\
\hline $\mathrm{SG}$ & 0.65 & 0.74 & 0.60 \\
\hline $\mathrm{P}(\mathrm{bar})$ & 19.8 & 14.1 & 13.7 \\
\hline $\mathrm{T}_{\mathrm{e}}\left({ }^{\circ} \mathrm{C}\right)$ & 132 & 122.5 & 50 \\
\hline
\end{tabular}

Optimization of energy Consumption:-

To get a better use of energy for the distillation column of industrial process, some parameters such, pressure, reflux ratio and feed tray must be taken into consideration in the determination of energy consumption in such systems [18]. In this section, we present the effects of all these parameters on the thermodynamic efficiency, energy consumption and the $\mathrm{CO}_{2}$ emission environment impact of stabilization column.

\section{Effect of pressure:-}

The parametric sensitivity study was tested for pressure, at the top of the column. By choosing different pressure values below 13 bar, we had tried to obtain the experimental data related to the boiling temperature, mol flow rates and the specific gravity (SG), at $15^{\circ} \mathrm{C}$ of LPG and gasoline. Note that, the pressure equal to 13 bar is usually applied in refinery. The result allowed us to conclude that the minimum pressure required at the top of the stabilization column is 9 bar. The simulation results given for this pressure are summarized in the Table 2. This table shows that, in general the SRK EOS allows a better simulation of the $T_{e}, N$ and SG for the LPG and Gasoline. For each pressure, thermodynamic efficiency was calculated and the results obtained are represented in fig. $3 \mathrm{a}$. This figure represents the variation of thermodynamic efficiency with pressure and shows that the optimal value is equal to 9 bar. The optimized value of pressure and that usually applied in refinery were used to run the stabilization column and to calculate heat flow of condenser and of reboiler. The results obtained are grouped in Table 3, which shows 
that for the use of a pressure equal to 9 bar, the heat flow of the reboiler decreases, which enables us to save 1.2 Gcal / h.

Table 2:- Simulation Results.

\begin{tabular}{|c|c|c|c|c|}
\hline & \multicolumn{2}{|c|}{ LPG } & \multicolumn{2}{c|}{ Gasoline } \\
\cline { 2 - 5 } & $\mathrm{V}_{\mathrm{c}}$ & $\mathrm{E}(\%)$ & $\mathrm{V}_{\mathrm{c}}$ & $\mathrm{E}(\%)$ \\
\hline $\mathrm{T}_{\mathrm{e}}\left({ }^{\circ} \mathrm{C}\right)$ & 51.89 & 3.78 & 122.68 & 0.15 \\
\hline $\mathrm{N}(\mathrm{Kmol} / \mathrm{h})$ & 10963 & 0.07 & 65332.08 & 0.06 \\
\hline $\mathrm{SG}$ & 0.56 & 6.67 & 0.70 & 5.41 \\
\hline
\end{tabular}

\section{Effect of reflux Ratio :-}

Simulation runs were carried out to calculate the variation of thermodynamic efficiency in function of reflux ratio at industrial and optimal pressure, respectively, and by keeping the other parameters fixed. The reflux ratio was varied from 1.5 to 4.5 , knowing that the value of reflux ratio usually used in refinery is equal to 2 . The results obtained are represented in fig.3b.This figure shows the comparison of variation of thermodynamic efficiency in function of reflux ratio and pressure. It is clear that for both pressure the two curves follow the same evolution but they present different maximum values. For the industrial pressure the reflux ratio is equal to 2.5 and corresponds to thermodynamic efficiency equal to 0.8 ; while for the optimal pressure the reflux ratio is equal to 3 and corresponds to thermodynamic efficiency equal to 1 . However, we recommended to use the values equal to 3 as optimal values for reflux ratio at 9 bar.

\section{Effect of feed tray of the Column:-}

The feed tray number of the stabilization column was varied from 11 to 20 in keeping all other parameters constant and tested the two pressure studied. The results obtained are shown in fig.4.c.As can be seen in this figure the two curves have different maximum thermodynamic efficiency for a feed tray number equal to 16 . This is the same value that generally used in refinery but good thermodynamic efficiency is obtained for pressure equal to 9.

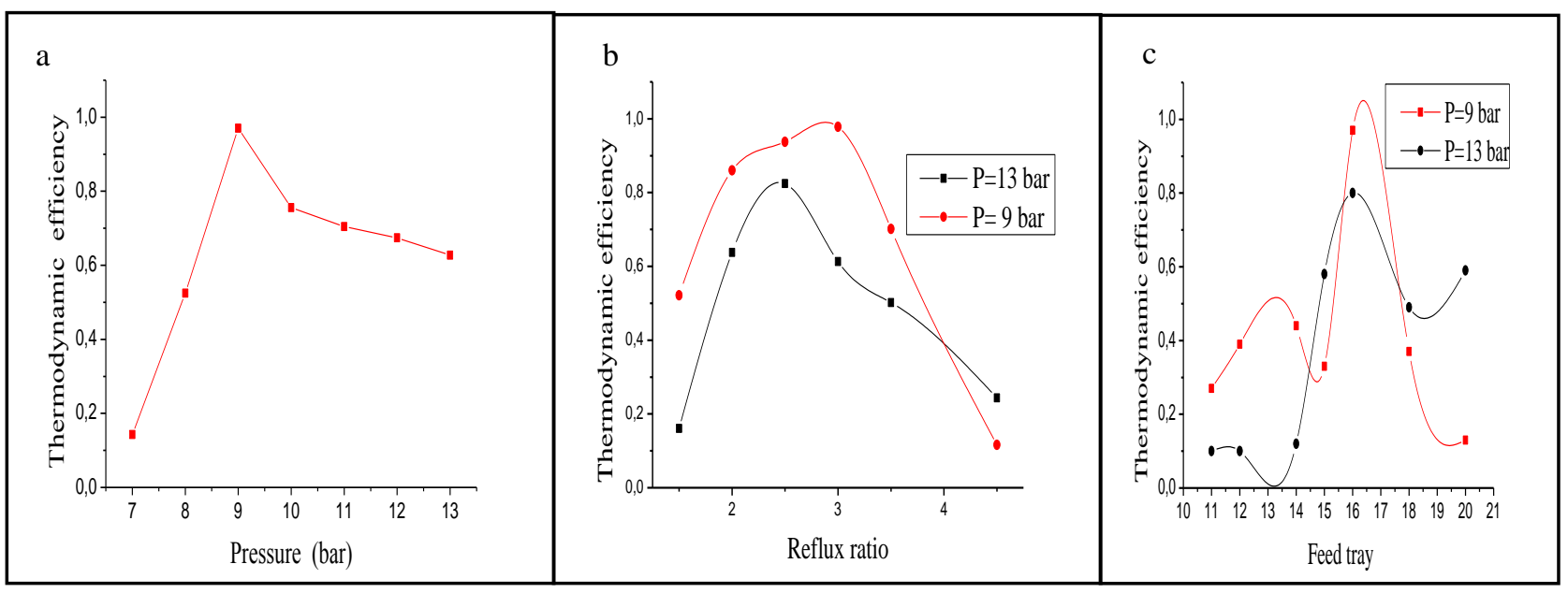

Figure 4:-Thermodynamic efficiency in function of a) Pressure b) Reflux ratio and pressure c) Feed tray and pressure ppressure

Column performance and $\mathrm{CO}_{2}$ Emission:-

Using equations 15 and16, the heat of reboiler, the energetic efficiency and $\mathrm{CO}_{2}$ emission were calculated before and after optimization of the stabilization column. Table 3 presents the results obtained and shows that after optimization, there is a reduction in energy consumption, improved energetic efficiency and $\mathrm{CO}_{2}$ Emission.

Table 3:- Comparison of the column performance and $\mathrm{CO}_{2}$ Emission, before and after optimization

\begin{tabular}{|c|c|c|}
\hline Column & Before optimization & After optimization \\
\hline $\mathrm{Q}_{\mathrm{r}}(\mathrm{G}$ cal $\mathrm{h})$ & 5.00 & 3,80 \\
\hline
\end{tabular}




\begin{tabular}{|c|c|c|}
\hline$\eta$ & 0.77 & 0.91 \\
\hline$\left[\mathrm{CO}_{2}\right]_{\text {Emiss }}(\mathrm{Kg} / \mathrm{h})$ & 464.14 & 352.71 \\
\hline Operation Cost $(€ 106 /$ year $)$ & 0.125 & 0.107 \\
\hline
\end{tabular}

The results allowed us to highlight the effect of operation parameters on the separation of products. From an economic point of view, stabilization of gasoline with optimal parameters may contribute to a decrease in expenses related to the energy consumption of reboiler, therefore reduction of carbon dioxide emission and impact environment.

\section{Cost Evaluation:-}

The required energy of cooling and heating for the industrial and optimized process was generated from electricity (Cooling) and energy of reboiler (heating). Those two energy resources were used to calculate the total operating cost of column [19]. The employed energy cost of steam generation was $0.098 \$ / \mathrm{kWh}$. This cost was estimated from the average price of industrial fuel, which equal to 492.145 \$ton [20]. The electricity cost used in the calculation was $0.167 \$ / \mathrm{kWh}$, obtained from Moroccan average cost energy [21]. The operating costs of conventional process and | optimized process pressure were estimated are represented in in Table.4.

\section{Conclusions:-}

In the present study, attention is given to get a better use of energy for the distillation column of petroleum fractions and reduction the environment impact by minimizing the $\mathrm{CO}_{2}$ emission and operation cost, especially the gasoline stabilization column. In a first time, equations to modeling this column, in the oil process are described, for each equilibrium stage. These equations are based on the mass and energy balances and VLE conditions. The SRK EOS was used to calculate thermodynamic properties of complex petroleum fluids. The accuracy of the model was tested successfully, by comparing the prediction of the boiling temperature, molar flow rates and the specific gravity at $15^{\circ} \mathrm{C}$ (SG) of LPG and gasoline against experimental data obtained from distillation column of Moroccan refinery.

In the second time, a technical feasibility study was followed to run the stabilization column at an optimum operation parameters and good thermodynamic efficiency. These results show the reduction of energy consumption, increasing energy efficiency and reducing $\mathrm{CO} 2$ emission, and reducing the operation costs of process in comparison to the conventional stabilization process. By applying the parametric sensitivity method the operation cost and $\mathrm{CO} 2$ emission of the industrial process were reduced about $14 \%$ and $24 \%$, respectively. 


\section{References:-}

1. Hoeven M. Energy and Climate Change. Inetrnational energy Agency. 2015.

2. Demirel Y. Sustainable Operations for Distillation Columns. Chemical Engineering \& Process Techniques 2013;1:1-15.

3. Alfredo T B, Pedro PM, Xavier LB, Isabel OP. A methodology for territorial distribution of $\mathrm{CO} 2$ emission reductions in transport sector, International Journal of Energy Research. 2011; 36: 1298-1313

4. ILKKa M, Juha T. Thermally Coupled Side-Column Configurations Enabling Distillation Boundary Crossing. 1. An Overview and a Solving Procedure. Ind. Eng. Chem. Res. 2009; 48: 6387-6404.

5. Alhajji M, Demirel Y. Energy and environmental sustainability assessment of a crude oil refinery by thermodynamic analysis, Int. J. Energy Res. 2015; 39:1925-1941.

6. Karimi S. 11th International Symposium On Process Systems Engineering - Pse 2012, 1st edition, national university of singapore. Singapore.

7. Biegler LT. Grossmann I E. Westerberg AW. Systematic methods of chemical process design. New Jersey: Prentice Hall Inc.; 1997.

8. Matsuda K, Kawazuishi K, Kansha Y, Fushimi C, Nagao M, Kunikiyo H, Masuda F, Tsutsumi A, Advanced energy saving in distillation process with self-heat recuperation technology. Energy 2011; 36:4640-4645.

9. William R, Morrow III, John M, Ali H, Eric M, Jayant S. Efficiency improvement and CO2 emission reduction potentials in the United States petroleum refining industry. Energy 2015; 93: 95-105.

10. Wauquier JP. Petroleum Refining-Separation Processes, Volume. 2 French Institute of Petroleum : Paris, 2000.

11. Rojey A, Jaffret C, Cornot-Gandolphe S, Durand B, Jullian S, Valais M. Natural gaz production processing and transpor, French Institute of Petroleum: Paris, 1997.

12. Gutiérrez-Guerra, J. Segovia-Hernández G, Hernández S. Reducing energy consumption and CO2 emissions in extractive distillation. Chemical engineering research and design. 2009; 8: 7145-152.

13. Gadalla MA, Olujic Z, Jensens P, Jobson M, Smith R. Reducing CO2 emissions and energy consumption of heat-integrated distillation systems. Environ. Sci. Technol 2005; 3:96860-6870 .

14. Lorenz T B. Nonlinear Programming Concepts, Algorithms, and Applications to Chemical Processes, Carnegie Mellon University, Pittsburgh, Pennsylvania. 2010

15. S. Sator and C.E. Chitour, "Equations of State Modifications for a Better Prediction of Thermodynamic Properties of Crude Oils", Oil \& Gas Science and Technology. 2001; 56: 1-12.

16. Soave G. Equilibrium constants from a modified Redkh-Kwong equation of state. Chem. Eng. Sci, 1972; 27:1197-1203.

17. Ould Brahim A, Abderafi S, Bounahmidi T. Parametric study on the energy efficiency of the stabilization column; 3rd International Renewable and Sustainable Energy Conference (IRSEC'15). DOI: 10.1109/IRSEC.2015.7454969. IEEE 2016; 1-5.

18. Demirel Y.. Thermodynamic Analysis of Separation Systems. Separation Science and Technology. 2010; 39: 3897-3942.

19. Ana M. Eliceche, M. Carolina Daviou, Patricia M. Hoch, Inmaculada Ortiz Uribe. Optimisation of azeotropic distillation columns combined with pervaporation membranes. Computers and Chemical Engineering 2002; 26 : 563-573.

20. Ministère de l'économie et des finances, projet de loi de finances pour l'année budgétaire 2016, rapport sur la compensation. Available from: http://www.finances.gov.ma; 2016.

21. Office National de l'Electricité 2016 .http://www.one.org.ma/ 